Tạp chí Khoa học ĐHQGHN: Khoa học Tự nhiên và Công nghệ, Tập 33, Số 2 (2017) 1-8

\title{
Phân tích in Silico họ gen Glutamate dehydrogenase ở cây đậu tương (Glycine max L.)
}

\author{
Cao Phi Bằng* \\ Khoa Khoa học Tụ nhiên, Trừ̀ng Đại học Hùng Vuơng, Phú Thọ, Việt Nam \\ Nhận ngày 30 tháng 3 năm 2015 \\ Chỉnh sửa ngày 16 tháng 4 năm 2015; Chấp nhận đăng ngày 28 tháng 6 năm 2017
}

\begin{abstract}
Tóm tắt: Glutamate dehydrogenase $(\mathrm{GDH}, \mathrm{EC}$ 1.4.1.2 4) là enzyme xúc tác phản ứng thuận nghịch khử amin hóa glutamate tới $\alpha$-ketoglutarate hoặc 2-oxoglutarate. Chúng tôi xác định được mười gen mã hóa GDH trong hệ gen của cây đậu tương. Các protein GDH suy diễn có kích thước 637 hoặc 411 amino acid, ngoại trừ GmGDH06. Phân tích cây phả hệ được xây dựng từ các GHD của đậu tương và các cây khác cho thấy các GDH của đậu tương được xếp vào hai nhóm, hai gen nhóm I và tám gen nhóm II. Các protein nhóm II có motif bảo thủ tín hiệu khu trú ti thể, motif bảo thủ gắn cơ chất đặc hiệu $\alpha$-ketoglutarate và vùng gắn đặc hiệu coenzyme NADH. Các protein nhóm I cũng có vùng gắn cơ chất đặc hiệu nhưng có vùng gắn coenzyme NADPH. Sự biểu hiện của các gen $G D H$ của cây đậu tương khác nhau ở các mô khác nhau. Bốn gen $G m G D H 03$, GmGDH04, GmGDH05và $G m G D H 07$ biểu hiện ở tất cả các mô ở tất cả các giai đoạn phát triển được nghiên cứu. Các $G m G D H$ biểu hiện ở mô sinh sản mạnh hơn ở mô sinh dưỡng, ngoại trừ $G m G D H 06$, gen biểu hiện đặc hiệu ở nốt sần.
\end{abstract}

Tù khóa: Glutamate dehydrogenase, biểu hiện gen, cây phả hệ, đặc trưng của gen, đậu tương.

\section{Mở đầu}

Đậu tương (Glycine max) là một trong những cây trồng quan trọng nhất và được trồng nhiều nơi trên thế giới. Hạt đậu tương chứa nhiều protein và dầu. Đậu tương là thực phẩm có lợi cho sức khỏe $[1,2]$. Một đặc điểm đáng chú ý là loài cây này còn có khả năng cố định nitơ tự do trong khí quyển nhờ hệ vi sinh vật cộng sinh trong bộ rễ của chúng. Nhờ giá trị cao, hệ gen của đậu tương đã được giải trình tự xong vào năm 2010 bởi tập thể các nhà khoa học Mỹ dẫn đầu bởi Stacey (Trung tâm Quốc

\footnotetext{
*ĐT.: 84-904922412.

Email: phibang.cao@hvu.edu.vn

https://doi.org/10.25073/2588-1140/vnunst.4503
}

gia về Công nghệ sinh học), Shoemaker (Nhóm nghiên cứu côn trùng trên cây ngũ cốc và Di truyền cây nông nghiệp USDA-ARS), Jackson (Khoa Nông học, Đại học Purdue), Schmutz (Trung tâm giải trình tự hệ gen HudsonAlpha), và Rokhsar (Viện nghiên cứu hệ gen). Phiên bản hệ gen của cây đậu tương hiện có kích thước xấp xỉ $975 \mathrm{Mb}$, gồm có 20 nhiễm sắc thể [3].

Glutamate dehydrogenase (GDH, EC 1.4.1.2 4) là enzyme xúc tác phản ứng thuận nghịch khử amin hóa glutamate tới $\alpha$ ketoglutarate hoặc 2-oxoglutarate nhờ sử dụng NADH hoặc NADPH như là coenzyme [4]. GDH có ở khắp các sinh vật từ vi khuẩn đến các sinh vật nhân chuẩn. Ở thực vật, enzyme này rất phong phú và có mặt ở nhiều cơ quan, 
định khu ở ti thể, lục lạp và dịch bào [4]. Glutamate dehydrogenase tham gia vào quá trình đồng hóa $\mathrm{NH}_{4}^{+}$ở thực vật cùng với hệ thống GS/GOGAT. Enzyme này tham gia vào sự cân bằng glutamate nội mô, amino acid giữ vai trò trung tâm trong nhiều quá trình trao đổi chất $[5,6]$. Các GDH thường liên quan tới tính chống chịu của thực vật thông qua cân bằng $\mathrm{N} / \mathrm{C}$ của thực vật [7]. Về cấu trúc, các GDH có mang hai vùng bảo thủ đặc trưng là vùng gắn Glutamate và vùng gắn $\mathrm{NAD}(\mathrm{P})$ [8]. Nhiều nghiên cứu gần đây đã chỉ ra rằng ở thực vật có ít nhất hai gen mã hóa cho GDH, một mã hóa cho dưới đơn vị $\alpha$ và một mã hóa cho dưới đơn vị $\beta$, hai dưới đơn vị này kết hợp với nhau theo các tỉ lệ khác nhau có thể tạo thành 7 dạng isozyme khác nhau [9]. Các họ GDH đã được phân tích ở Arabidopsis [10], ở lúa [11], ở cà chua [12]. Tuy nhiên, những nghiên cứu về sự điều hòa biểu hiện của các gen $G D H$ còn chưa nhiều. Đến nay, sự biểu hiện của $G D H$ được biết là có đáp ứng với các tác nhân bất lợi vô sinh như hạn, mặn, nhiệt độ, kim loại nặng và sự thiếu carbon $[5,13,14]$. Rất gần đây, sự biểu hiện của các gen $G D H$ trong quá trình chín của quả cà chua cũng được báo cáo $[12,15]$. Tuy nhiên chưa có nghiên cứu toàn diện về họ gen $G D H$ trên quy mô hệ gen của cây đậu tương, loài cây có khả năng cố định $\mathrm{N}_{2}$.

Trong nghiên cứu này, chúng tôi hướng tới việc xác định các gen mã hóa cho các GDH trong hệ gen của cây đậu tương. Đồng thời chúng tôi trình bày các kết quả phân tích về các đặc tính hóa-lí và cấu trúc cũng như sự biểu hiện của các gen này thông qua phân tích kết quả RNAseq (giải trình tự ARN).

\section{Phương pháp nghiên cứu}

2.1. Cơ sở dũ liệu về các trình tư hệ gen và RNAseq ở cây đậu tưong

Trình tự hệ gen của cây đậu tương được lấy từ Schmutz et al. (2010) [3]. Dữ liệu RNAseq được lấy từ Severin et al. (2010) [16].

\subsection{Xác định các gen thuộc họ GDH ở cây đậu} tuong

Các protein GDH của cây Arabidopsis thaliana $[7,10,14,17,18]$ được dùng làm khuôn dò để tìm kiếm các gen tương đồng trên toàn hệ gen của cây đậu tương nhờ chương trình TBLASTN.

\subsection{Xây dựng cây phả hệ}

Cây phả hệ được xây dựng từ các protein GDH nghiên cứu nhờ phần mềm MEGA5 [19] sau khi chúng được sắp dãy bằng MAFFT [20].

\subsection{Phân tích các đặc điểm hóa - lí}

Các đặc điểm vật lí, hóa học của các gen/protein được phân tích bằng các công cụ của ExPASy [21]. Cấu trúc exon/intron được xây dựng nhờ GSDS 2.0 [22].

\subsection{Khảo sát sụ biểu hiện gen}

Sự biểu hiện của các gen được phân tích qua kết quả RNAseq (giải trình tự tập hợp ARN thông tin) của cây đậu tương [16]

\section{Kết quả và thảo luận}

\subsection{Xác định ho gen GDH ở cây đậu tưong và đặc điểm của chúng}

Khi sử dụng chương trình TBLASTN với khuôn dò là các protein GDH của $A$. thaliana, chúng tôi đã xác định các GDH của cây đậu tương là một họ đa gen nhỏ với 10 gen. Protein suy diễn của các gen này mang vùng bảo thủ tương ứng với mã số $\mathrm{PF} 02812$ và $\mathrm{PF} 00208$ trong ngân hàng gen. Đây vốn là hai vùng bảo thủ đặc trưng cho các GDH đã biết. So về kích thước của họ gen, cây đậu tương có họ GDH lớn hơn so với của cây $A$. thaliana, cây cà chua và cây lúa. Thực vậy, số lượng gen $G D H$ được báo cáo của các loài trên chỉ là 4 gen $[11,12,18]$.

Các đặc điểm vật lí của các gen và protein suy diễn được thể hiện trong bảng 1. Các gen này quy định các protein có kích thước rất gần 
nhau, có độ dài 411 và 412 amino acid, ngoại trừ GmGDH04, GmGDH05 và GmGDH06. Hai protein đầu có 637 amino acid trong khi protein thứ ba chỉ có 330 amino acid. Ngoại trừ ba protein này, các protein khác có khối lượng dao động khoảng $44,5 \mathrm{kD}$, gần giống với các $\mathrm{GDH}$ đã biết của Bryopsis maxima [23], Nicotiana plumbaginifolia [24], A. thaliana [10]. Các protein GDH của cây đậu tương có tính axit yếu đến trung tính.

Các gen $G D H$ của cây đậu tương mã hóa không liên tục, trong gen có từ 6 tới 14 intron (hình 1). Gen GmGDHO6 có 6 intron, hai gen $G m G D H 04$ và $G m G D H 05$ có 14 intron, các gen còn lại có 8 intron. Đặc điểm này giống với các gen $G D H$ của cây cà chua [12].

Bảng 1. Các gen thuộc họ GDH của cây đậu tương và đặc điểm của chúng

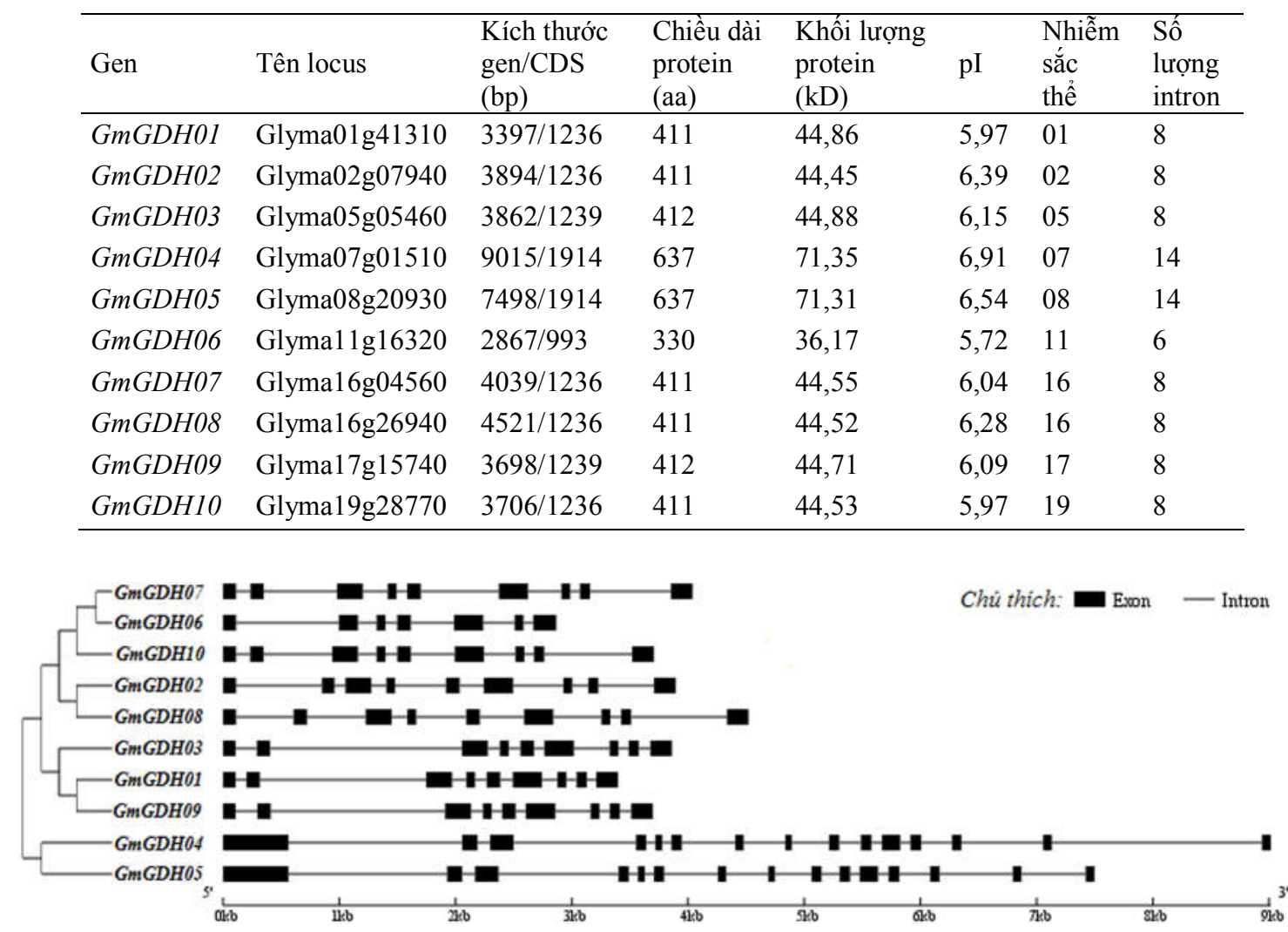

Hình 1. Cấu trúc exon/intron của các gen GDH của cây đậu tương.

3.2. Các motif bảo thủ của các $G D H$ ở cây đậu tương

Sự sắp dãy các protein GDH của cây đậu tương cho phép phát hiện các motif bảo thủ của chúng. Các motif bảo thủ được đánh dấu trong khung hoặc được tô màu nền (hình 2). Ở đầu amin (N-terminal), các GDH của cây đậu tương có mang motif bảo thủ là peptide tín hiệu định hướng protein vào trong ti thể (đóng khung nét đứt), ngoại trừ GmGDH04 và GmGDH05. Motif gắn đặc hiệu cơ chất $\alpha$-ketoglutarate (được đóng khung nét liền) có ở tất cả các $\mathrm{GDH}$. Vùng gắn $\mathrm{NAD}(\mathrm{P}) \mathrm{H}$ được tô nền xám, trong đó, GmGDH04 và GmGDH05 có vùng gắn đặc hiệu NADPH (GxGx2Ax10G), các protein còn lại của cây đậu tương có vùng gắn đặc hiệu NADH (GxGx2Gx10G). Các Motif 
bảo thủ này của các GmGDH tương đồng cao với các GDH của một số loài thực vật khác như lúa [11] thuốc lá [24], cà chua [12]. Kết quả sắp dãy các protein cũng cho phép phát hiện vùng bị xóa ở GmGDH06. Vùng này nằm giữa hai motif peptide tín hiệu định hướng protein vào trong ti thể và motif gắn đặc hiệu cơ chất (hình 2). Vùng bị mất này giải thích tại sao GmGDH06 có kích thước ngắn hơn và có số lượng intron ít hơn các GmGDH khác.

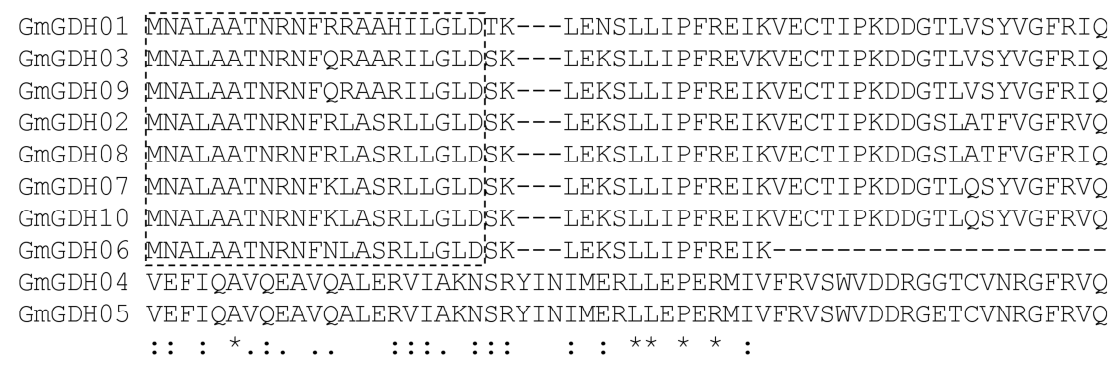

GmGDH01 HDNARGPMKGGIRYHPEVDPDEVNALAQLMTWKTAVADIPYGGAKGGIGCNPRDLSVSEL GmGDH03 HDNARGPMKGGIRYHPEVDPDEVNALAQLMTWKTAVADIPYGGAKGGIGCNPRDLSISEL GMGDHO9 HDNARGPMKGGIRYHPEVDPDEVNALAQLMTWKTAVADIPYGGAKGGIGCNPRDLSISEL GmGDH02 HDNARGPMKGGIRYHPEVEPDEVNALAQLMTWKTAVANIPYGGAKGGIGCDPAKLSVSEL GMGDH08 HDNARGPMKGGIRYHPEVEPDEVNALAQLMTWKTAVANIPYGGAKGGIGCDPADLTVSEL GMGDH07 HDNARGPMKGGIRYHPEVDPDEVNALAQLMTWKTAVANIPYGGAKGGIGCDPAELSISEL GmGDH10 HDNARGPMKGGIRYHPEVDPDEVNALAQLMTWKTAVANIPYGGAKGGIGCDPAELSISEL

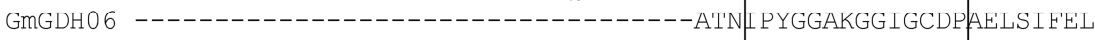
GmGDH0 4 FNQSMGPCRGGIRFHPSMNLSVAKFLGFEQTLKNALSPYKLGGAAGGSDFDPKGKSDNEI GmGDH05 FNQSMGPCRGGIRFHPSMNLSVAKFLGFEQTLKNALSPYKLGGAAGGSDFDPKGKSDNEI

GMGDHO1 ERLTRVFTQKIHDLIGIQRDVPAPDMGTNSQTMAWILDEYSKFHGHSPAVVTGKPIDLGG GmGDH03 ERLTRVFTQKIHDLIGIQRDVPAPDMGTNAQTMAWILDEYSKFHGHSPAVVTGKPIDLGG GMGDH09 ERLTRVFTQKIHDLIGVQRDVPAPDMGTNAQTMAWILDEYSKFHGHSPAVVTGKPIDLGG GMGDH02 ERLTRVFTQKIHDLIGVQTDVPAPDMGTGPQTMAWILDEYSKFHGHSPAVVTGKPIELGG GmGDH08 ERLTRVFTQKIHDLIGVQTDVPAPDMGTGPQTMAWILDEYSKFHGHSPAVVTGKPVELGG GmGDH07 ERLTRVFTQKIHDLIGTHTDVPAPDMGTGPQTMAWILDEYSKFHGYSPAVVTGKPIDLGG GMGDH10 ERLTRVFTQKIHDLIGTHTDVPAPDMGTGPQTMAWILDEYSKFHGYSPAVVTGKPIDLGG GmGDH06 DRLTRVFTQKIHDLIGTHTDVPAPYMGTGPQTMAWILDEYSKFHGYSPVVVTGKPIDLGG GMGDHO 4 MRFCQSFMSEMYRYLGPDKDLPSEEMGVGTREMGYLFGQYRRLAGHFQGSFTGPRIFWSG GMGDH05 MRFCQSFMSEMYRYLGPDKDLPSEEMGVGTREMGYLFGQYRRLAGHFQGSFTGPRIEWSG ${ }^{\star}:{ }^{\star} .:::{ }^{\star} .{ }^{\star}:{ }^{\star}:{ }^{\star} \ldots .{ }^{\star} .::: .{ }^{\star}::^{\star}: \quad{ }^{\star} \quad:{ }^{\star}$

GMGDH01 SLGREAATGLGVIFATEALFAEYGKS ISDMTFVIQGFGNVGTWAAKS IYERGGKVIAVSD GmGDH03 SLGREAATGLGVVFATEALFAEYGKS ISDHTFI IQGFGNVGWWAKS I FERGGKVIAVSD GmGDH09 SLGREAATGLGVVFATEALFAEYGKS ISDHTFVIQGFGNVGTWAAKS I FERGGKVIAVSD GmGDH02 SLGRDAATGRGVLFATEALLKEHGMSLSGQRLVIQGFGNVGSWAAKLISEKGGKVVAVSD GmGDH08 SLGRDAATGRGVLFATEALLKEHGMSVSGQRFI IQGFGNVGSWAAQLISEKGGKVVAVSD GmGDH07 SLGRDAATGRGVLFATEALLNEYGKSVSGQRFVIQGFGNVGSWAAQLISNKGGKVVAVSD GmGDH10 SLGRDAATGRGVLFATEALLNEYGKSVSGQRFVIQGFGNVGSWAAQLISEKGGKVVAVSD GmGDH0 6 SLGRDVATGWGVLFATEALLNEYGKSVSGQRFVIQGFGNVGSWAAQLISDKGGKVVVVSD GMGDH04 SSLRPEATGYGLVFEAQLMLADMNKELKGLRCAVSGSGKI AMHVLEKLIAYGALPISVSD GMGDH05 SSLRPEATGYGLVFFAQLMLADMNKELKGLRCVVSGSGKIAMHVLEKLIAYGALPISVSD

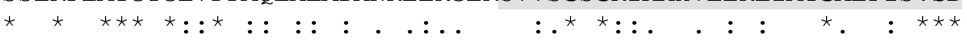

Hình 2. Kết quả sắp dãy vùng bảo thủ của các protein GDH của cây đậu tương. Dấu đánh dấu các amino acid bảo thủ, các amino acid tín hiệu định hướng protein vào trong ti thể được đóng khung nét đứt, vùng gắn $\alpha$-ketoglutarate được đóng khung nét liền, vùng gắn $\mathrm{NAD}(\mathrm{P}) \mathrm{H}$ được tô nền xám. 
3.3. Phân tích cây phả hệ và phân loại các Glutamate dehydrogenase

Cây phả hệ được xây dựng từ các protein GDH của các loài đậu tương, Arabidopsis, cà chua và lúa được giới thiệu trong hình 3 . Các protein này xếp ở hai nhánh lớn của cây phả hệ, trong đó có một nhánh nhỏ, chỉ gồm có hai trình tự của cây đậu tương, một của cây lúa và một của cây Arabidopsis. Nhánh còn lại phân chia thành nhiều nhánh nhỏ hơn. Sự phân bố của các GDH trong cây phả hệ cho phép phân chia các GDH của cây đậu tương thành hai nhóm chính, tương tự như ở các loài thực vật khác $[11,18]$. Nhóm I gồm có hai gen $G m G D H 04$ và $G m G D H 05$, xếp cùng nhánh với $A t G D H 4$ và $O s G D H 4$. Tám gen còn lại của cây đậu tương thuộc về nhóm II. Trong nhóm này, các GDH của cây đậu tương được chia thành hai phân nhóm nhỏ hơn khi chưng phân bố ở hai phân nhánh khác nhau, phân nhóm IIa với các gen $G m G D H 02$, GmGDHO6, GmGDHO7, $G m G D H 08$ và $G m G D H 10$, các gen thuộc phân nhóm IId là GmGDH01, GmGDHO3 và GmGDH09. Hiện tượng tương tự cũng được thấy ở các loài khác như Arabidopsis (IIa và IIc), thuốc lá (IIa và IIc) và lúa (IIa và IIb). Sự phân chia các GDH thành hai nhóm khác nhau trên cây phả hệ phù hợp với cấu trúc của chúng, nhóm I gồm các protein có motif bảo thủ gắn NADPH (GxGx2Ax10G) trong khi nhóm II gồm các protein có motif bảo thủ gắn $\mathrm{NADH}$ (GxGx2Gx10G).

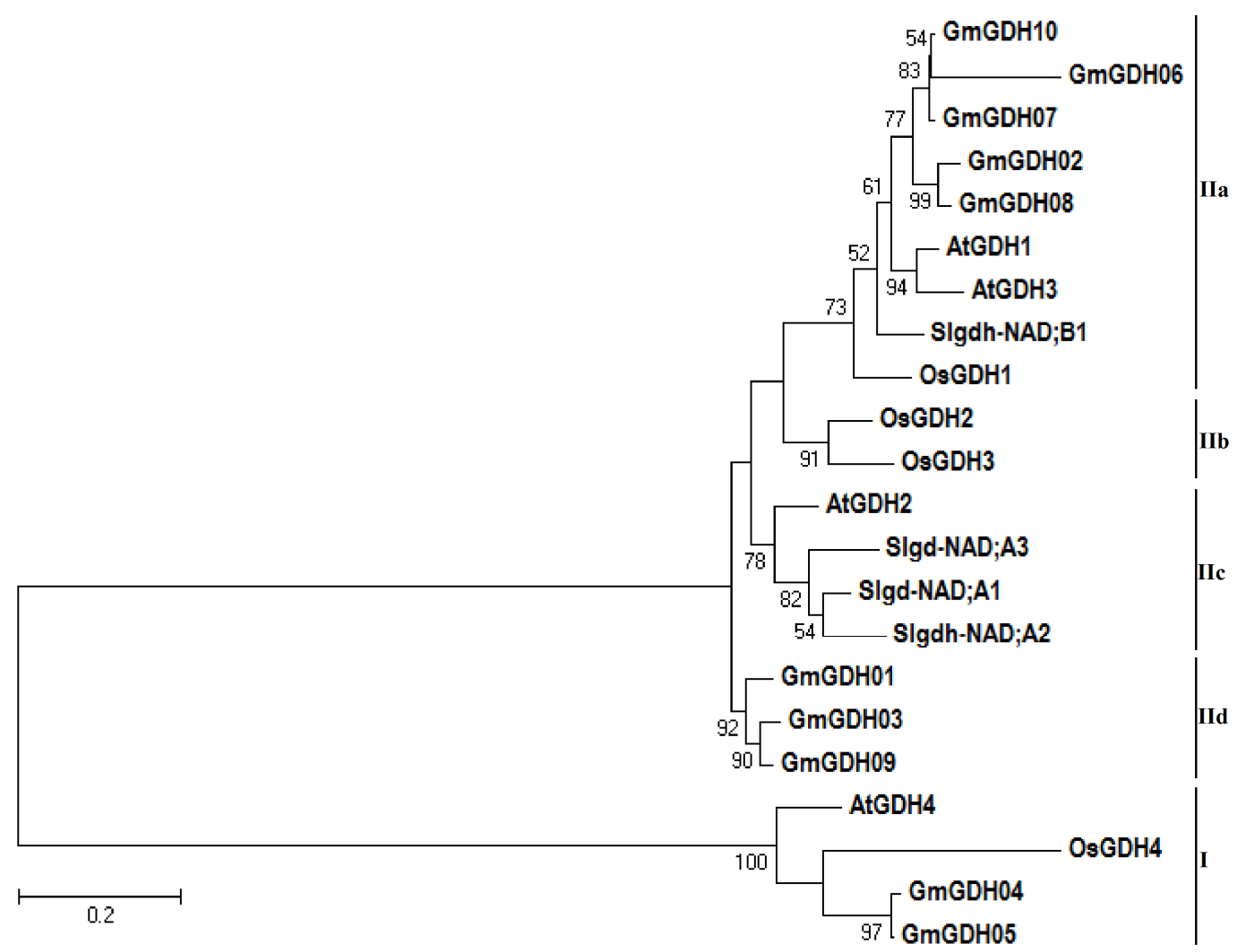

Hình 3. Cây phả hệ được xây dựng từ các GDH của cây đậu tương $(\mathrm{Gm})$, cây $A$. thaliana $(\mathrm{At})$ cây cà chua $(\mathrm{Sl})$ và cây lúa (Os). Cây phả hệ được xây dựng với các tham biến: thuật toán Maximum Likelihood, mô hình JonesTaylor-Thornton (JTT), phương pháp Bootstrap với 1000 lần lặp lại, giá trị bootstrap (\%) được thể hiện trên mỗi nhánh (giá trị nhỏ hơn 50 không được thể hiện), tỷ lệ xích là số amino acid thay thế trên một vị trí. 
Cây phả hệ cũng cho phép phát hiện nhiều sự kiện nhân gen $G D H$ trong hệ gen (Whole Genome Duplication, WGD) của cây đậu tương, hình thành nên các gen $G m G D H 04$ và $G m G D H 05, \quad G m G D H 02$ và $G m G D H 08$, $G m G D H 07$ và cặp $G m G D H 06$ với $G m G D H 10$, $G m G D H 01$ và cặp $G m G D H 03$ với $G m G D H 09$. Các sự kiện nhân gen cũng xảy ra ở các loài khác, nhưng chỉ đối với các gen thuộc nhóm II.

\subsection{Phân tích sự biểu hiện gen}

Chúng tôi phân tích sự biểu hiện gen của các gen $G D H$ qua kết quả RNAseq (giải trình tự các $\mathrm{ARN}$ thông tin) thu được từ các mô, cơ quan của cây đậu tương ở các giai đoạn phát triển khác nhau, gồm mô lá, mô hoa, mô quả (ở ba thời điểm), mô hạt (ở 7 thời điểm khác nhau), mô rễ và nốt sần. Bản đồ nhiệt giới thiệu sự biểu hiện của các gen (hình 4 ). Tất cả các gen $G D H$ của cây đậu tương đều biểu hiện ở ít nhất một loại mô, mức độ biểu hiện khác nhau tùy từng gen và thay đổi tùy loại mô khác nhau.
Hai gen $G m G D H 02$ và $G m G D H 06$ là những gen biểu hiện yếu nhất, gen thứ nhất chỉ biểu hiện ở hoa trong khi gen thứ hai chỉ biểu hiện ở nốt sần. Các gen $G m G D H 03, G m G D H 04$, $G m G D H 05$ và $G m G D H 07$ là những gen biểu hiện ở tất cả các mô ở tất cả các giai đoạn phát triển được nghiên cứu. Xét ở từng mô khác nhau, ba gen GmGDH04, GmGDH05 và GmGDH07 biểu hiện mạnh nhất ở lá, gen GmGDH07 biểu hiện mạnh nhất ở hoa, quả rễ và nốt sần, gen $G m G D H 01$ biểu hiện mạnh nhất ở hạt. Với mỗi gen, mức độ biểu hiện cao nhất được thấy ở các mô sinh sản (ngoại trừ GmGDH06). Sự biểu hiện khác nhau của các gen $G D H$ ở các mô khác nhau đã được báo cáo ở Arabidopsis [14], cà chua [12]. Ngoài ra, những nghiên cứu về sự biểu hiện gen $G D H$ dưới ảnh hưởng của các điều kiện môi trường đã được thực hiện ở lúa (trong điều kiện thiếu hụt nitơ và phospho) [11], ở thuốc lá (trong điều kiện thiếu hụt đường, nitơ, mặn và nhiễm độc kim loại nặng) [13, 24].

\begin{tabular}{|c|c|c|c|c|c|c|c|c|c|c|c|c|c|c|c|}
\hline n & 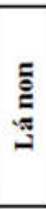 & $\stackrel{\text { อ̆ }}{\underline{\underline{\theta}}}$ & 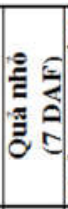 & 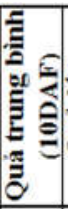 & $\frac{5}{20}$ & $=\underline{\underline{\theta}}$ & 홀 & $=\frac{a}{a}$ & 플 & $=\frac{0}{a}$ & 흘 & 퐇 & $\stackrel{\text { שֶ }}{\dddot{2}}$ & 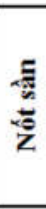 & 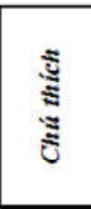 \\
\hline GmGDHO1 & 0 & 1 & 4 & 1 & 1 & 18 & 27 & 17 & 24 & 16 & 22 & 12 & 1 & 0 & 30 \\
\hline GmGDHO2 & 0 & 3 & 0 & 0 & 0 & 0 & 0 & 0 & 0 & 0 & 0 & 0 & 0 & 0 & 25 \\
\hline GmGDHO3 & 1 & 3 & 2 & 2 & 2 & 4 & 10 & 5 & 3 & 1 & 2 & 1 & 2 & 1 & 20 \\
\hline GmGDHO4 & 5 & 7 & 5 & 4 & 3 & 3 & 4 & 3 & 4 & 1 & 5 & 2 & 6 & 3 & 15 \\
\hline GmGDHO5 & 5 & 8 & 5 & 6 & 4 & 4 & 3 & 3 & 5 & 2 & 4 & 3 & 8 & 6 & 10 \\
\hline GmGDHO6 & 0 & 0 & 0 & 0 & 0 & 0 & 0 & 0 & 0 & 0 & 0 & 0 & 0 & 1 & 5 \\
\hline GmGDHO7 & 5 & 53 & 12 & 12 & 5 & 2 & 3 & 4 & 11 & 8 & 13 & 4 & 9 & 7 & 0 \\
\hline GmGDHO & 0 & 2 & 0 & 0 & 0 & 0 & 1 & 1 & 1 & 0 & 0 & 0 & 0 & 0 & \multirow{3}{*}{$\begin{array}{c}D A F= \\
\text { ngày } \\
\text { sau thy } \\
\text { tinh }\end{array}$} \\
\hline GmGDH09 & 4 & 2 & 5 & 4 & 2 & 5 & 16 & 7 & 4 & 3 & 3 & 2 & 5 & 0 & \\
\hline GmGDH10 & 0 & 1 & 1 & 0 & 1 & 4 & 3 & 1 & 1 & 2 & 8 & 4 & 1 & 3 & \\
\hline
\end{tabular}

Hình 4. Sự biểu hiện của các gen $G D H$ của cây đậu tương trong các mô nghiên cứu.

\section{Kết luận}

Trong toàn hệ gen của cây đậu tương, có mười gen mã hóa các $\mathrm{GDH}$, trong đó có hai gen thuộc nhóm I (nhóm NADPH-GDH) và 8 gen thuộc nhóm II (nhóm NADH-GDH). Các gen này mã hóa không liên tục với 14 intron hoặc 8 intron, ngoại trừ gen $G m G D H 06$. Các gen này quy định các protein có kích thước khá tương đồng, 637 amino acid hoặc 411 amino acid, ngoại trừ $G m G D H 6$ do có một vùng bị xóa. Phân tích cây phả hệ cho thấy các GDH của cây 
đậu tương được xếp vào hai nhóm giống như ở nhiều thực vật khác, nhóm I (hai gen $G m G D H 04$ và $G m G D H 05$ ) và nhóm II (gồm các gen còn lại). Các protein nhóm II có motif bảo thủ tín hiệu khu trú ti thể ở đầu amin, motif bảo thủ gắn cơ chất đặc hiệu $\alpha$-ketoglutarate và vùng gắn đặc hiệu coenzyme NADH. So với các protein nhóm II, các protein nhóm I cũng có vùng gắn cơ chất đặc hiệu nhưng vùng gắn coenzyme khác biệt nhẹ khi gắn với $\mathrm{NADPH}$. Sự biểu hiện của các gen trong họ $G D H$ của cây đậu tương khác nhau ở các mô khác nhau. Gen GmGDH02 biểu hiện đặc hiệu ở hoa trong khi GmGDH06 biểu hiện đặc hiệu ở nốt sần. Chỉ bốn gen $G m G D H 03, G m G D H 04, G m G D H 05$ và GmGDH07 biểu hiện ở tất cả các mô ở tất cả các giai đoạn phát triển được nghiên cứu. Ngoại trừ gen $G m G D H 06$, các gen còn lại đều biểu hiện ở các mô sinh sản mạnh hơn ở các mô sinh dưỡng. Những kết quả nghiên cứu này bổ sung các thông tin khoa học về cấu trúc, phân loại, và vai trò của các gen $G D H$ của cây đậu tương, mở đường cho việc tách dòng gen và phân tích đầy đủ chức năng của các gen trong họ $G D H$ ở cây đậu tương.

\section{Lời cảm ơn}

Công trình này được hoàn thành với sự hỗ trợ kinh phí từ chương trình nghiên cứu khoa học cơ bản của Trường Đại học Hùng Vương, tỉnh Phú Thọ.

\section{Tài liệu tham khảo}

[1] M. Friedman and D. L. Brandon, Nutritional and health benefits of soy proteins, J Agric Food Chem 49 (2001) 1069-86.

[2] K. Liu, Soybeans as functional foods and ingredients, AOCS Publishing (2005).

[3] J. Schmutz, S. B. Cannon, J. Schlueter, J. Ma, T. Mitros, W. Nelson, et al., Genome sequence of the palaeopolyploid soybean, Nature, 463 (2010) 178183.

[4] F. Dubois, T. Tercé-Laforgue, M.-B. GonzalezMoro, J.-M. Estavillo, R. Sangwan, A. Gallais, et al., Glutamate dehydrogenase in plants: is there a new story for an old enzyme?, Plant Physiol and Biochem 41 (2013) 565-576.

[5] B. G. Forde and P. J. Lea, Glutamate in plants: metabolism, regulation, and signalling, in $\mathrm{J}$ Exp Bot 58 (2007) 2339-58.

[6] B. G. Forde, Glutamate signalling in roots, in $\mathrm{J}$ Exp Bot. 65 (2014) 779-787.

[7] J. X. Fontaine, T. Terce-Laforgue, P. Armengaud, G. Clement, J. P. Renou, S. Pelletier, et al., Characterization of a NADH-dependent glutamate dehydrogenase mutant of Arabidopsis demonstrates the key role of this enzyme in root carbon and nitrogen metabolism, in Plant Cell 24 (2012) 4044-4065.

[8] P. J. Baker, K. L. Britton, P. C. Engel, G. W. Farrants, K. S. Lilley, D. W. Rice, et al., Subunit assembly and active site location in the structure of glutamate dehydrogenase, Proteins 12 (1992) 75-86.

[9] K. A. Loulakakis and K. A. RoubelakisAngelakis, Plant $\quad \mathrm{NAD}(\mathrm{H})$-Glutamate Dehydrogenase Consists of Two Subunit Polypeptides and Their Participation in the Seven Isoenzymes Occurs in an Ordered Ratio, Plant Physiol 97 (1991) 104-111.

[10] F. J. Turano, S. S. Thakkar, T. Fang, and J. M. Weisemann, Characterization and expression of $\mathrm{NAD}(\mathrm{H})$-dependent glutamate dehydrogenase genes in Arabidopsis, Plant Physiol 113 (1997) 1329-1341.

[11] X. Qiu, W. Xie, X. Lian, and Q. Zhang, Molecular analyses of the rice glutamate dehydrogenase gene family and their response to nitrogen and phosphorous deprivation, Plant Cell Rep 28 (2009) 1115-1126.

[12] G. Ferraro, S. Bortolotti, P. Mortera, A. Schlereth, M. Stitt, F. Carrari, et al., Novel glutamate dehydrogenase genes show increased transcript and protein abundances in mature tomato fruits, in J Plant Physiol. 169 (2012) 899-907.

[13] F. M. Restivo, Molecular cloning of glutamate dehydrogenase genes of Nicotiana plumbaginifolia: structure analysis and regulation of their expression by physiological and stress conditions, Plant Science 166 (2004) 971-982.

[14] Y. Miyashita and A. G. Good, NAD(H)dependent glutamate dehydrogenase is essential for the survival of Arabidopsis thaliana during dark-induced carbon starvation, in J Exp Bot, 59 (2008) 667-680.

[15] G. Tsilikochrisos, G. Tsaniklidis, C. Delis, N. Nikoloudakis, and G. Aivalakis, Glutamate dehydrogenase is differentially regulated in 
seeded and parthenocarpic tomato fruits during crop development and postharvest storage, Scientia Horticulturae 181 (2015) 34-42.

[16] A. J. Severin, J. L. Woody, Y. T. Bolon, B. Joseph, B. W. Diers, A. D. Farmer, et al., RNASeq Atlas of Glycine max: a guide to the soybean transcriptome, BMC Plant Biol 10 (2010) 160.

[17] M. P. Purnell, D. S. Skopelitis, K. A. RoubelakisAngelakis, and J. R. Botella, Modulation of higher-plant $\mathrm{NAD}(\mathrm{H})$-dependent glutamate dehydrogenase activity in transgenic tobacco via alteration of beta subunit levels, Planta 222 (2005) 167-180.

[18] R. Inokuchi, K. I. Kuma, T. Miyata, and M. Okada, Nitrogen-assimilating enzymes in land plants and algae: phylogenic and physiological perspectives, in Physiol Plant. 116 (2002) 1-11.

[19] K. Tamura, D. Peterson, N. Peterson, G. Stecher, M. Nei, and S. Kumar, MEGA5: molecular evolutionary genetics analysis using maximum likelihood, evolutionary distance, and maximum parsimony methods, Mol Biol Evol 28 (2011) 2731-2739.
[20] K. Katoh and D. M. Standley, MAFFT multiple sequence alignment software version 7: improvements in performance and usability, Mol Biol Evol 30 (2013) 772-780.

[21] E. Gasteiger, C. Hoogland, A. Gattiker, M. R. Wilkins, R. D. Appel, and A. Bairoch, Protein identification and analysis tools on the ExPASy server, in The proteomics protocols handbook, Springer, (2005) 571-607.

[22] A. Y. Guo, Q. H. Zhu, X. Chen, and J. C. Luo, GSDS: a gene structure display server, Yi Chuan 29 (2007) 1023-1026.

[23] R. Inokuchi, K. Motojima, Y. Yagi, K. Nakayama, and M. Okada, Bryopsis maxima (Chlorophyta) glutamate dehydrogenase: multiple genes and isozymes, Journal of Phycology 35 (1999) 1013-1024.

[24] A. Ficarelli, F. Tassi, and F. M. Restivo, Isolation and characterization of two cDNA clones encoding for glutamate dehydrogenase in Nicotiana plumbaginifolia, Plant Cell Physiol 40 (1999) 339-342.

\title{
In Silico Analysis of Glutamate Dehydrogenase Gene Family in Soybean (Glycine max L.)
}

\author{
Cao Phi Bang \\ Faculty of Natural Sciences, Hung Vuong University, Phu Tho, Vietnam
}

\begin{abstract}
Glutamate dehydrogenase (GDH, EC 1.4.1.2 4) are the enzymes which catalyze reversible deamination reaction of L-glutamate to 2-oxoglutarate or $\alpha$-ketoglutarate $(\alpha-\mathrm{KG})$. We identified a total of ten GDH encoded genes in soybean genome. The full length sequence of predicted proteins had 637 or 411 amino acids, except GmGDH06. Analysis of phylogenetic tree constructed from GDH proteins of soyean and other plants showed that the soybean GDH were classified into two groups, the group I inclued two genes and the group II included eight genes. The group II proteins possessed a mitochondrial target motif, a conserved specific $\alpha$-ketoglutarate binding and a specific NADH coenzyme binding region. The group I proteins also included a specific subtrat binding but they contained a NADPH coenzyme binding. The expression of soybean $G D H$ genes was dissimilar in different tissues. Four genes GmGDH03, GmGDHO4, GmGDHO5 and GmGDHO7 expressed in all tissues at all studied development stages. In addition, all soybean $G D H$ genes expressed stronger in reproductive tissues than in vegetative tissues, except GmGDHO6 which specifically expressed in nodules.
\end{abstract}

Keywords: Glutamate dehydrogenase, gene expression, phylogenetic tree, gene characterization, soybean. 